\title{
KVALITETA ŽIVOTA PARAPLEGIČARA
}

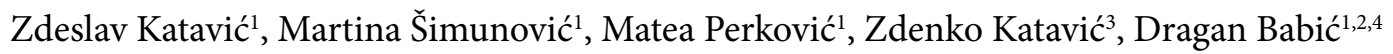 \\ ${ }^{1}$ Fakultet zdravstvenih studija Sveučilišta u Mostaru \\ ${ }^{2}$ Medicinski fakultet Sveučilišta u Mostaru \\ ${ }^{3}$ Specijalistička ordinacija za psihijatriju Dr. mr. sc. Zdenko Katavić \\ ${ }^{4}$ Klinika za psihijatriju Sveučilišne kliničke bolnice Mostar \\ 88000 Mostar, Bosna i Hercegovina
}

Rad je primljen 10.10. 2016. $\quad$ Rad je recenziran 20.10.2016. Rad je prihvaćen 03.11.2016.

\section{SAŽETAK}

UVOD: Poznato je da je kvaliteta života paraplegičara kao i drugih težih oboljenja u odnosu na opću zdravu polpulaciju smanjena i da društvo kontinuirano pokušava raditi na njenom poboljšanju.

CILJ: Ispitati kvalitetu života paraplegičara i usporediti je sa kvalitetom života kroničnih duševnih bolesnika.

ISPITANICI I METODE: Ispitnu skupinu činilo je 30 bolesnika sa dijagnozom paraplegije, a kontrolnu skupinu 30 kroničnih duševnih bolesnika liječenih na klinici psihijatriju SKB Mostar. U svrhu istraživanja korišten je upitnik općih i sociodemografskih podataka osobne izrade, namjenski sačinjen za ovo istraživanje, te upitnik kvalitete života Svjetske zdravstvene organizacije WHOQOL-BREF.

REZULTATI: Utvrđeno je da su ispitanici iz skupine s paraplegijom nešto bolje ukupne kvalitete života od ispitanika iz skupine s kroničnim duševnim bolestima, ali razlika nije statistički značajna. U obje ispitivane skupine zastupljeniji je ženski spol, ispitanici s kroničnim duševnim bolestima su statistički značajno starije dobi $(\mathrm{p}=0,002)$. Analizom rezultata pokazalo se da ispitanici iz skupine s paraplegijom imaju viši stupanj obrazovanja u odnosu na ispitanike iz skupine s kroničnim duševnim bolestima. Ispitanici iz skupine s kroničnim duševnim bolestima su nešto boljeg tjelesnog zdravlja, dok su ispitanici iz skupine s paraplegijom, bez statistički značajne razlike, boljeg psihičkog zdravlja te bolji u socijalnim odnosima.

ZAKLJUČAK: Paraplegičari imaju nešto bolju ukupnu kvalitetu života od kroničnih duševnih bolesnika ali razlika nije statistički značajna

Ključne riječi: kvaliteta života, paraplegičar

Osoba za razmjenu informacija:

Zdeslav Katavić E-mail: zdeslav.katavic@gmail.com

\section{UVOD}

Kvaliteta života je sintagma kojom se služe različite struke, a koristi se i u svakodnevnom govoru. Tom se pojmu pridaju vrlo različita značenja. U medicini, kvaliteta života uglavnom će označavati stupanj očuvanih funkcija bolesnika, u ekonomiji - životni standard, dok političari i politolozi naglašavaju zajamčene slobode i prava građana te civilizacijska postignuća kao što su dostupnost obrazovanja i zdravstvene zaštite. Osnovni cilj istraživanja kvalitete života je prepoznavanje čimbenika koji doprinose ostvarivanju ciljeva i potencijala pojedinaca te življenju željenog životnog cilja (1). Procjena kvalitete života naročito je važna kod bolesnika $s$ kroničnim

bolestima, poremećajima i oštećenjima kao što su i kornični duševni bolesnici i paraplegičari (2). Tijekom povijesti definicije i mjerenje kvalitete života uvelike su se razlikovale i mijenjale. U prvoj polovici prošlog stoljeća različite pokazatelje materijalne dobrobiti uzimalo se u obzir kao pokazatelje kvalitete života. Što je materijalna razina života u nekoj zemlji bila viša, to je život državljana smatran boljim. Šezdesetih godina promijenio se pristup te se pokušalo zahvatiti i drugačije pokazatelje kvalitete života, što se materijaliziralo u tzv. „pokretu društvenih indikatora" i dovelo do široke primjene koncepta u društvenim znanostima i različitim područjima javnog života (3). 
Objektivni pokazatelji, kao što su stopa nezaposlenosti, stopa smrtnosti novorođenčadi, broj radnih sati u tjednu i udio stanovništva koje se nalazi ispod granice siromaštva, predstavljaju uvjete i činjenice o nekoj društvenoj sredini. S druge strane, subjektivni pokazatelji se temelje na doživljaju pojedinca i njegovom vrednovanju društvenih uvjeta te uključuju zadovoljstvo životom, zadovoljstvo poslom koji osoba obavlja i sl. (4). Promjene u tim pokazateljima interpretiraju su kao poboljšanje odnosno pogoršanje kvalitete života u nekom društvu. Razvila su se dva različita pristupa istraživanju kvalitete života: skandinavski, koji uzima u obzir objektivne pokazatelje razine življenja ili kvalitete života društva kao cjeline te američki, koji naglašava subjektivne pokazatelje kvalitete života (5).

Tijekom povijesti u literaturi o kvaliteti života nalazimo brojne definicije. Danas je također prisutan veliki broj različitih definicija i modela kvalitete života. Cummins navodi da kvaliteta života podrazumijeva i objektivnu i subjektivnu komponentu. Subjektivna kvaliteta života uključuje sedam domena: materijalno blagostanje, emocionalno blagostanje, zdravlje, produktivnost, intimnost, sigurnost i zajednicu. Objektivna komponenta uključuje kulturno relevantne mjere objektivnog blagostanja (6). Svjetska zdravstvena organizacija (SZO) definira kvalitetu života kao pojedinčevu percepciju pozicije u specifičnom kulturološkom, društvenom i okolišnom kontekstu te percepciju sustava vrijednosti u kojem živi u odnosu na ciljeve, očekivanja, standarde i probleme sredine (7).

Mnoge tehnike trenutno dostupne za mjerenje kvalitete života bazirane su na upitnicima i vrednovane unutar određenog kulturnog konteksta. Pri tome ne možemo biti sigurni da bi upitnik primjenjiv za jednu kulturu bio primjenjiv za drugu. Jedan od načina rješavanja ovog problema je korištenje objektivnih mjera kvalitete života s pretpostavkom da mogu biti primjenjene u više kultura i da su one valjani pokazatelji kvalitete života (8). Većina ljestvica i upitnika namjenjenih mjerenju kvalitete života, kao i metode za njihovu analizu, ne dozvoljavaju slobodan izbor odgovora ispitanika i takvi instrumenti su često standardizirani na uzorcima različitim od populacije koja se procjenjuje (9). Postoje brojni instrumenti kojima se obuhvaća i mjeri kvaliteta života povezana $s$ domenom zdravlja, a može ih se podijeliti u tri skupine. Prvu skupinu čine upitnici kojima se zahvaća veći broj područja kvalitete života te su oni stoga uglavnom višedimenzionalni. Među instrumentima ove vrste, često se koriste: profil učinka bolesti (Sickness In Inpact Profile), upitnik za samoprocijenu zdravstvenog stanja (Short form helath survejy, SF-36) i upitnik kvalitete života SZO-a (The World Health Organization Quality of Life Insturment) $(10,11,12)$. Drugu skupinu čine instrumenti vezani uz točno određene bolesti, razvijeni za specifičnu uporabu među pacijentima sličnih tegoba. Kod pacijenata oboljelih od artritisa kvaliteta života ispituje se Skalom za mjerenje utjecaja oboljenja od artritisa (Arthritis Inpact Measurement Scale). Kod pacijenata oboljelih od raka upotrebljava se Skala Europske organizacije za liječenje oboljelih od raka (European Organization for Reasearch on Treatment of Cancer) $(13,14)$. Treću skupinu instrumenata čine utjecaji pojedinačnih domena na kvalitetu života, npr. utjecaj depresivnosti. Primjer ove vrste upitnika je Beckov inventar depresivnosti (Beck Depression Inventor) (15).

Razvojem istraživanja kvalitete života, znanstvenici su došli do spoznaje kako objektivne i subjektivne mjere nisu međusobno isključive te kako je radi potpunijeg razumijevanja koncepta najbolje primijeniti kombinaciju objektivnih i subjektivnih mjera zbog metodoloških razloga (16,17). Kombinacija subjektivnih i objektivnih pokazatelja naročito dolazi do izražaja kod geografskih studija kvalitete života.

Govoreći o paraplegiji, obično mislimo na spinalni oblik, iako lokalizacija lezije može biti i cerebralna. Spinalna paraplegija može biti spastična s hipertonijom muskulature, pojačanim tetivnim refleksima i uočljivim patološkim refleksima (babinski), a nastaje oštećenjem centralnih neurona u meduli spinalis. Ozljeda perifernog neurona uzrokuje atoniju muskulature, arefleksiju i izostanak patoloških refleksa te je stoga nazivamo flakcidnom spinalnom paraplegijom. Najbrojnijim etiološkim činbenicima pripadaju traume, zatim bolesti medule spinalis (upalne i degenerativne), tumori, mišićne bolesti i 
drugi rijeđi čimbenici. Traumatska paraplegija, za razliku od drugih, nastaje ubrzo nakon traume, praćena je spinalnim šokom, prestankom svih funkcija vezanih za medulu spinalis i stoga je svaka paraplegija u početku flakcidna ili mlohava. Kao motorni simptomi javljaju se pareze i paralize segmenata ispod razine lezije. Simptomi na senzitivnom planu su hipoestezije i najčešće anestezije, koje se prostorno ne moraju poklapati s motornim ispadima, jer postoji mogućnost ozljede medule i perifernih živaca, a i preklapanje spinalnih živaca na periferiji. Uz anestezije dodira redovito izostaje i osjet za toplinu i bol što je vrlo važno u primjeni električnih i toplinskih terapijskih postupaka, što su najčešći uzroci opeklina kod paraplegičara (18).

Kronični duševni bolesnici su oni kojima je zbog emocionalno-voljnih i/ili intelektualnih oštećenja tijekom duljeg razdoblja narušena razina funkcioniranja na osobnom, međuljudskom, obiteljskom, socijalnom i profesionalnom planu. Kronični duševni bolesnici u odnosu na pojedine dijagnostičke kategorije izrazito su heterogena populacija. Pomoću tri dimenzije kojima je omeđen pojam kroničnog duševnog bolesnika (dijagnoza, stupanj disabiliteta i trajanje hospitalizacije) možemo se orijentirati o rasprostranjenosti pojave (19). Najveći broj osoba koje zbog dugotrajnog mentalnog poremećaja pate od težeg disabiliteta dolaze iz redova shizofrenih bolesnika, shizoafektivnog poremećaja, bipolarno afektivnog poremećaja te iz populacije bolesnika oštećenih kroničnim moždanim sindormom (alkoholizam, cerebralne traume, senilni procesi i sl.). Udio depresivnih bolesnika u populaciji kroničara je veći nego što pokazuju podaci o prevalenciji. Udio ostalih pacijenata s primarnim poremećajem osobnosti i neurotika je malen. Simptomi u kroničnih duševnih bolesnika variraju u odnosu na osnovni mentalni poremećaj. Afektivno osiromašenje, manjak inicijative i motiviranosti, nezainteresiranost, hipobulija, anhedoničnost te smanjenje kognitivnih funkcija bitno obilježavaju profil kroničnog duševnog bolesnika u psihopatološkom smislu. Oko trećine psihijatrijskih bolesnika (pretežno psihotični bolesnici) liječi se do kraja svog života, tako da je pitanje kvalitete njihova života duži niz godina tema ne samo psihijatara i ostalih zdravstvenih radnika nego i raznih segmenata društva koji se o njima brinu. Istraživanja kvalitete života kronično oboljelih psihijatrijskih bolesnika pokazuju nižu kvalitetu života u odnosu na opću populaciju (20).

Cilj ovog rada je ispitati kvalitetu života paraplegičara i usporediti je sa kvalitetom života kroničnih duševnih bolesnika

\section{ISPITANICI I METODE}

\section{Ispitanici}

Ispitnu skupinu činilo je 30 bolesnika sa dijagnozom paraplegije. Dijagnoza je postavljena od strane iskusnog liječnika specijaliste i potvrđena adekvatnim dijagnostičkim metodama. Kontrolnu skupinu činilo 30 kroničnih duševnih bolesnika liječenih na klinici za psihijatriju SKB Mostar. Dijagnoza je također postavljena od strane iskusnog psihijatra na temelju MKB 10 (shizofrenija, bipolarni afektivni poremećaj, shizoafektivni poremećaj).

\section{Metode}

U ispitivanju su korišteni sljedeći upitnici:

1. Upitnik općih i sociodemografskih podataka osobne izrade, namjenski sačinjen za ovo istraživanje (sadržavao je opća pitanja: dob, spol, stupanj obrazovanja i bračno stanje).

2. Upitnik kvalitete života Svjetske zdravstvene organizacije WHOQOL-BREF je kraći oblik upitnika WHOQOL-100. Odabrane su 24 čestice iz originalnog upitnika, po jedna iz svake od 24 čestice koje opisuju kvalitetu života te je odabrana po jedna čestica za kvalitetu života u cjelini i za opće zdravlje. Upitnik u cijelosti sadrži 26 čestica. Kao rezultat upitnika WHOQOL-BREF dobiva se profil kvalitete života koji polazi od modela koji objašnjava kvalitetu života kroz 4 područja: tjelesno zdravlje, psihičko zdravlje, socijalni odnosi i okolina. Rezultati su dobiveni kombinacijom 24 čestice upitnika. Rezultat u svakom području izražava se kao prosjek odgovora na česticama koje je opisuju. Čestica opće kvalitete života i općeg zdravlja razmatraju se zasebno. Odgovori za svaku česticu daju se na skali Likertovog tipa od 1-5, gdje 1 označava najmanje slaganje, a 5 označava najveće slaganje sa česticom (1). 


\section{Statistička obrada podataka}

Za statističku analizu rabljen je programski sustav SPSS for Windows (inačica 17.0., SPSS Inc, Chicago, Illinois, SAD) i Microsoft Excel (inačica 11.0., Microsoft Corporation, Redmond, WA, SAD). Rezultati za kategorijske varijable su izraženi kao frekvencija i postotaka, za parametrijske varijable kao aritmetička sredina i standardna devijacija. Za testiranje razlike među kategorijskim varijablama korišten je hi kvadrat test, a među parametrijskim varijablama Student t-test za nezavisne uzorke. Razina značajnosti od $\mathrm{p}<0,05$ je uzeta kao statistički značajna.

\section{REZULTATI}

Tablica 1. Raspodjela ispitanika s obzirom na sociodemografske karakteristike

\begin{tabular}{|c|c|c|c|c|c|c|}
\hline & \multicolumn{4}{|c|}{ Skupina } & \multirow{3}{*}{$\chi^{2}$} & \multirow{3}{*}{$p$} \\
\hline & \multicolumn{2}{|c|}{ Paraplegija } & \multicolumn{2}{|c|}{ Kronični duševni bolesnici } & & \\
\hline & $\mathrm{N}$ & $\%$ & $\mathrm{~N}$ & $\%$ & & \\
\hline Spol & & & & & 0,069 & 0,792 \\
\hline Muški & 11 & 36,7 & 13 & 43,3 & & \\
\hline Ženski & 19 & 63,3 & 17 & 56,7 & & \\
\hline Izobrazba & & & & & 3,048 & $0,262^{*}$ \\
\hline Osnovna škola & 0 & 0,0 & 3 & 10,0 & & \\
\hline Srednja škola & 18 & 60,0 & 18 & 60,0 & & \\
\hline Visoka škola & 12 & 40,0 & 9 & 30,0 & & \\
\hline
\end{tabular}

Iz tablice je vidljivo da su u obje ispitivane skupine zastupljenije ženske osobe i vidljivo je da su ispitanici iz skupine s paraplegijom obrazovaniji od ispitanika iz skupine kroničnih duševnih bolesnika, ali među ispitivanim skupinama nije bilo statistički značajne razlike.

Iz slike br. 1 je vidljiva statistički značajna razlika u odnosu na dob ispitanika ( $\mathrm{p}=0,002)$, prosječna dob ispitanika iz skupine s paraplegijom je oko 43 godine, a ispitanika iz skupine s kroničnim duševnim bolestima oko 53 godine.

Iz slike br. 2 je vidljivo da ispitanici iz skupine $s$ paraplegijom imaju nešto bolju ukupnu kvalitetu života u odnosu na ispitanike s kroničnim duševnim bolestima, ali među ispitivanim skupinama nema statistički značajne razlike.

Tablica 2. Raspodjela ispitanika u odnosu na kvalitetu života

\begin{tabular}{lcccccc}
\hline & \multicolumn{6}{c}{ Skupina } \\
& \multicolumn{1}{c}{ Paraplegija } & Kronični duševni bolesnici & $\mathrm{t}$ & $\mathrm{p}$ \\
\cline { 2 - 7 } & $\bar{X}$ & SD & $\bar{X}$ & SD & \\
\hline Tjelesno zdravlje & 14,17 & 2,79 & 14,72 & 3,49 & 0,677 & 0,501 \\
Psihičko zdravlje & 15,22 & 2,57 & 14,07 & 3,08 & 1,577 & 0,120 \\
\hline Socijalni odnosi & 13,82 & 3,00 & 13,51 & 3,75 & 0,355 & 0,724 \\
\hline Okolǐ̌ & 13,40 & 2,60 & 13,47 & 3,46 & 0,084 & 0,933 \\
\hline WHOQ0L-BREF ukupno & 14,33 & 2,78 & 13,33 & 3,84 & 1,156 & 0,253 \\
\hline
\end{tabular}

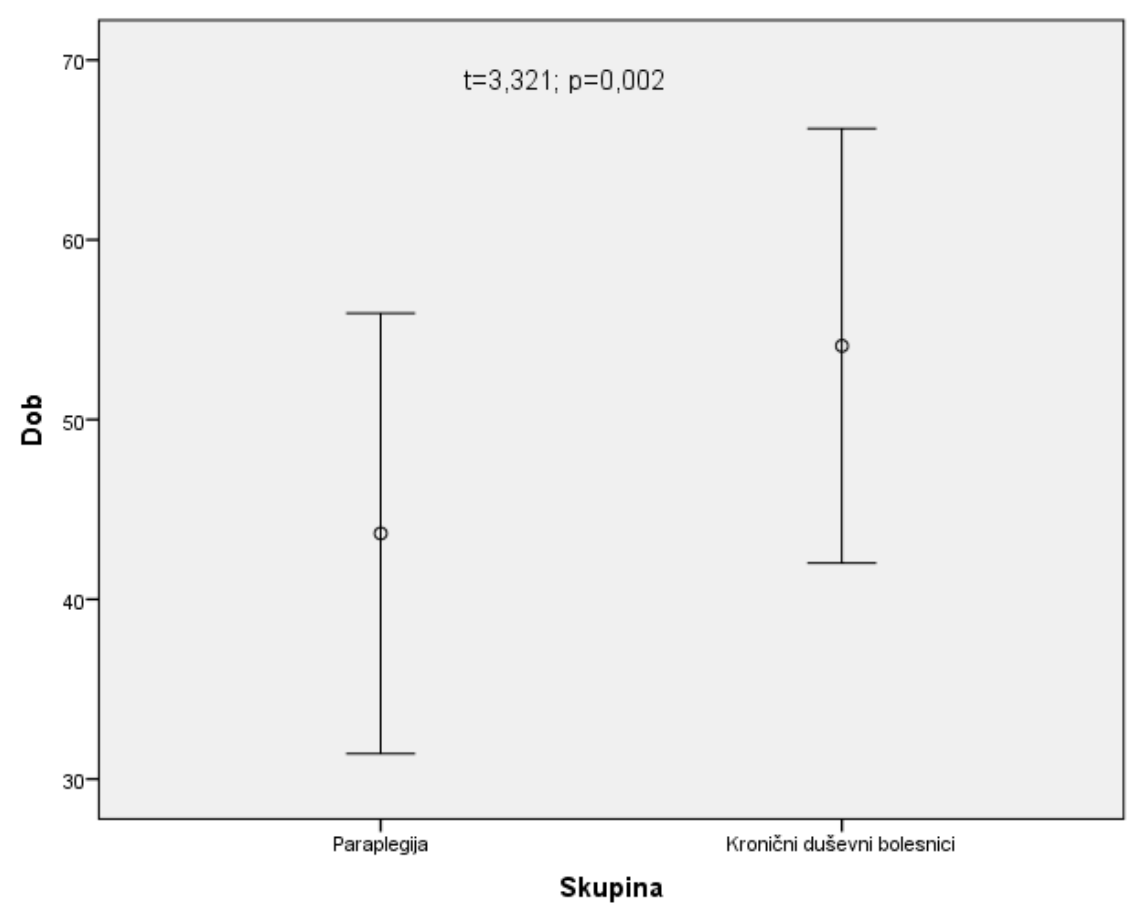

Slika 1. Raspodjela ispitanika s obzirom na dob 


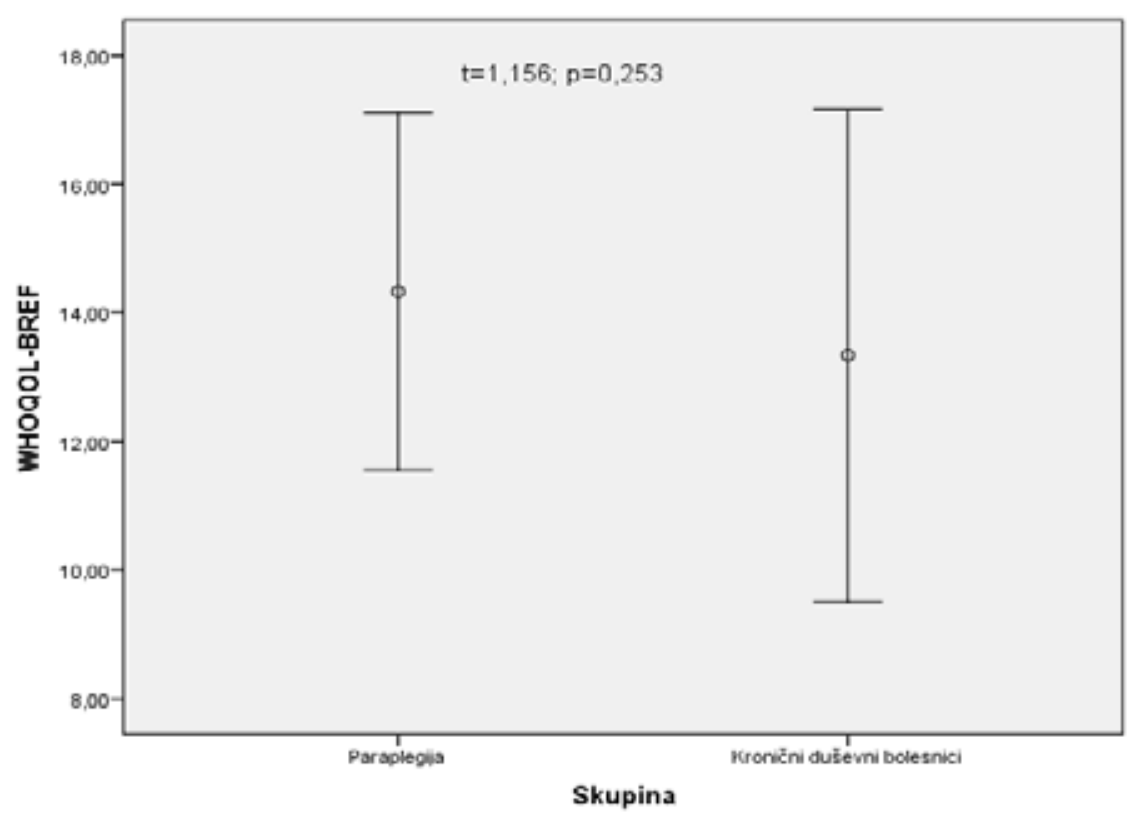

Slika 2. Raspodjela ispitanika s obzirom na ukupnu kvalitetu života

U odnosu na ispitivane sastavnice kvalitete života (tjelesno zdravlje, psihičko zdravlje, socijalni odnosi i okoliš) kao i na kvalitetu života ukupno, između ispitivanih skupina nije bilo statistički značajne razlike.

\section{RASPRAVA}

U ovom radu cilj nam je bio ispitati kvalitetu života paraplegičara i usporediti je s kvalitetom života kroničnih duševnih bolesnika. Rezultatima dobivenim ovim istraživanjem utvrđeno je da su ispitanici iz skupine s paraplegijom nešto bolje ukupne kvalitete života od ispitanika iz skupine s kroničnim duševnim bolestima ali nije bilo statistički značajne razlike. $\mathrm{U}$ obje ispitivane skupine zastupljeniji je ženski spol, dok je u dobi ispitanika s kroničnim duševnim bolestima zabilježena statistički značajna razlika u odnosu na ispitanike iz skupine s paraplegijom ( $\mathrm{p}=0,002$ ). Analizom rezultata pokazalo se da ispitanici iz skupine s paraplegijom imaju viši stupanj obrazovanja u odnosu na ispitanike iz skupine s kroničnim duševnim bolestima. Ispitanici iz skupine s kroničnim duševnim bolestima su, očekivano, nešto boljeg tjelesnog zdravlja, dok su ispitanici iz skupine s paraplegijom, bez statistički značajne razlike, boljeg psihičkog zdravlja te bolji u socijalnim odnosima, a utjecaj okoline je gotovo identičan u obje ispitivane skupine.

Ovi rezultati su komplementarni s rezultatima istraživanja kvalitete života paraplegičara u Indiji u kojem je prosječna dob ispitanika s paraplegijom identična kao u našem istraživanju, te dobiveni rezutati ukazuju na vrlo niske vrijednosti ukupne kvalitete života. Indijski istraživači navode kako postoji statistički značajna i snažna pozitivna veza između fizičke aktivnosti i poboljšanja kvalitete života u svim domenama (21). Rezultati jednog istraživanja kvalitete života kroničnih duševnih bolesnika u SAD-u također su pokazali kako nema statistički značajne razlike u kvaliteti života osoba s kroničnim fizičkim i osoba s kroničnim psihičkim bolestima, osim u jednoj od komponenti kvalitete života - obiteljskim odnosima (22). Također, istraživanje provedeno u Los Angelesu o kvaliteti života kroničnih duševnih bolesnika pokazuje i isto tako naglašava, poput prethodno navedenog istraživanja, kako je za poboljšanje kvalitete njihova života potrebna kontinuirana skrb u postizanju bolje osobne sigurnosti i samostalnosti, boljih socijalnih odnosa, financija i bolje organizacije slobodnog vremena (24). U razvijenim zemljama stoga se ulažu sve veća sredstva kako bi zdravstveni radnici, u suradnji s ostalim 
srodnim stručnjacima, mogli razvijati programe koji obogaćuju upravo ove aspekte kvalitete života.

Za razliku od ovog istraživanja, studija kvalitete života paraplegičara i tetraplegičara u SAD-u 1994. g. pokazala je da $86 \%$ ispitanika sa visokom ozljedom kralježnice ocijenjuje kvalitetu svog života prosječnom ili iznad prosječnom, što je u suprotnosti s našim rezultatima (25).

Ovo istraživanje pokazuje kako je percepcija kvalitete života kod osoba s paraplegijom i osoba s kroničnim duševnim bolestima sličnija percepciji takvih osoba u slabije razvijenim zemljama. Rezultati pokazuju lošu ukupnu kvalitetu života kod paraplegičara i još lošiju kod kroničnih duševnih bolesnika što jasno ukazuje na potrebu daljnih istraživanja o različitim mogućnostima poboljšanja kvalitete života tih osoba kroz bolju skrb, društvenu brigu, medicinsko zbrinjavanje te razvijanje društvene svijesti o ovim bolestima i razbijanje stigme koja ih prati u društvu, posebno kod kroničnih duševnih bolesti. Ovakvi rezultati još jednom nedvojbeno ukazuju na poznatu povezanost tijela i duše i potvrđuju važnost i značenje holističkog odnosno integralnog pristupa u medicini tj. da se čovjeka (bolesnika) uvijek mora promatrati u cijelni, a ne samo jedan njegov dio ili određeni organ.

\section{ZAKLJUČCI}

1. Rezultati istraživanja pokazuju lošu ukupnu kvalitetu života ispitanika obaju skupina.

2. Ispitanici iz skupine kroničnih duševnih bolesnika imaju, iako statistički neznačajnu, ipak lošiju ukupnu kvalitetu života od ispitanika iz skupine paraplegičara.

3. Ispitanici iz skupine s paraplegijom imaju viši stupanj obrazovanja, njihova dob je statistički značajno manja u odnosu na ispitanike iz skupine s kroničnim duševnim bolestima i imaju bolje razvijene socijalne odnose.

4. Ispitanici iz skupine s kroničnim duševnim bolestima imaju lošije psihičko zdravlje u odnosu na ispitanike iz skupine s paraplegijom, dok ispitanici s paraplegijom imaju lošije fizičko zdravlje, iako u obje kategorije ne postoji statistički značajna razlika.

\section{LITERATURA}

1. Bejaković P, Kaliterna Lipovčan LJ. Quality of life in Croatia: Key ndings from national research, Dublin: European Foundation for the Improvement of Living and Working Conditions. 2007.

2. Veenhoven R. „Happy life-expectancy: a conprehensive measure of quality-of-life in nations." Social indicators research, 1996;39(1):1-58.

3. Noll, Heinz-Herbert. Social Indicators and Social Reporting: Internacional Experience; 1996. Pristupljeno: 09.09.2016. Dostupno na: http:// www.ccsol.ca/noll1.html.

4. Diener E, Suh EM, Lucas R, Smith HL. Subjective Well-Being: Three Decades of Progres 1999.

5. Robinson MD, Clore GL. Belief and feeling: Evidence for an accessibility model of emotional self-report. Psychological Bulletin 2002;128:934960.

6. WHOQOL Group. The World Helath Organization Quality of life assessment (WHOQOL): Position Paper from the World Health Organization. Soc Sci Med 1995;41:1403-9.

7. Liu B. Quality of life indicators: A preliminary investigation. Social Indicators Research, 1974;1:187-208.

8. O'Boyle CA. The Schedule for the Evaluation of Individual Quality of Life (SEIQoL). International Journal of Mental Health 1994;23:3-23.

9. Bergner M, Bobbit R, Carter W, Gilson B. The Sickness Impact Profile: Development and final revision of a health status measure. Medical Care 1981;19:787-805.

10. Ware JE. SF-36 Health Survey: Manual \& interpretation guide. Boston, MA: The Health Institute. New Englend Medical Center. 1993.

11.The World Health Organization Quality of Life Group: The World Health Organization Quality of Life Assessment (WHOQOL-BREF): Introduction, administration, scoring and generic version of the assessment. Field trial version. Geneva: Programme on mental health. 1996.

12. Meenan RF, Gertman PM, Mason JH. Measuring health status in arthritis: The Arthritis Impact Measurement Scales. Arthritis and Rheumatism 1980;23:146-152. 
13. Arson NK, Ahmendzai S, Bergman B, Bullinger M, Cull A, Duez NJ, Filiberti A, Fletchtner H, Fleishman SB, De Haes JCJM, Kaasa S, Klee M, Osoba D, Razavi D, Rofe PB, Schraub S, Sneeuw K, Sullivan M, Takeda F. The European Organization for Research and Treatment of Cancer QLQ-C30: A quality of life instrument for use in international clinical trials in oncology. Journal of the National Cancer Institute 1993;85:365-376.

14. Beck AT, Ward CH, Mendelson M, Mock J, Erbaugh J. An inventory for measuring depression. Archives of General Psychiatry 1961;4:561-571.

15. Veenhoven, R. Advances in the understanding of happiness, Revue quebecoise de psychologie, 1997;18(2):29-74.

16. Noll, H. H. (2000.) Social Indicators and Social Reporting: The International Experience. (internet). Pristupljeno: 14.09.2016. dostupno na: http://www.ccsd.ca/noll1.html

17. Cutter S. Rating places, A geographer 's view on Quality of Life, Association of American Geographers, Resource publications in geography, Washington D. C; 1985.

18. Majkić M. Klinička kineziterapija. Inmedia:Zagreb; 1997.
19. Minkoff K. „A Map of the Chronic Mental Patient" in Task Force Report of the American Psychiatric Association Ad Hoc Committee on the Chronic Mental Patient, Washington DC: American Psychiatric Association 19978;11-37.

20. Frančišković T, Moro Lj i sur. Psihijatrija. Zagreb. Medicinska naklada; 2009.

21. National Institute of Rehabilitation Training \& Research, Cuttack, Odisha, India. Physical Activity and Quality of Life among Adults with Paraplegia in Odisha, India. (internet). Pristupljeno: 28.09.2016. dostupno na: https://www.ncbi.nlm. nih.gov/pmc/articles/PMC4746044/

22. Atkinskon M, Zibin S, Chuang S. Characterizing Quality of Life Among Patients With Chronic Mental Illness: A Critical Examination of the Self-Report Methodology. American Juournal of Psychiatry; 1997.

23. Manns PJ. Components of Quality of Life for Persons with Quadriplegic and Paraplegic Spinal Cord Injury. Quality Health Research; 2001.

24. Gerhart KA i sur. Annalas of Emergency Medicine, 1994;23:807-812. 


\title{
THE QUALITY OF LIFE OF PARAPLEGIC PATIENTS
}

\author{
Zdeslav Katavić́ ${ }^{1}$, Martina Šimunović ${ }^{1}$, Matea Perković ${ }^{1}$, Zdenko Katavić ${ }^{3}$, Dragan Babić ${ }^{1,2,4}$ \\ ${ }^{1}$ Faculty of Health Studies, University of Mostar \\ ${ }^{2}$ Faculty of Medicine, University of Mostar \\ ${ }^{3}$ Specialist Practice for Psychiatry Zdenko Katavić, MD, MSc \\ ${ }^{4}$ Department of Psychiatry, University Clinical Hospital Mostar \\ 88000 Mostar, Bosnia and Herzegovina
}

\begin{abstract}
INTRODUCTION: It is known that the quality of life of paraplegics and other severe ailments is severely reduced when compared to the general healthy population, and the society continuously tries to work on its improvement.

OBJECTIVE: Examine the quality of life of paraplegics and compare it to the quality of life of chronic mental patients.

SUBJECTS AND METHODS: The test group consisted of 30 patients diagnosed with paraplegia, and the control group of 30 chronic mental patients treated at the Department of Psychiatry at the University Clinical Hospital in Mostar. For the purpose of the research we used a questionnaire with general and socio-demographic data, customized specifically for this research, as well as the quality of life questionnaire of the World Health Organization WHOQOL-BREF.

RESULTS: It was found that subjects from the group with paraplegia have a slightly better quality of life when compared to the patients from the group with chronic metal illnesses, but the difference was not statistically significant. Both test groups had more female respondents, and those with chronic mental disorders were significantly older $(p=0.002)$. The result analysis showed that the respondents from the group with paraplegia have a higher level of education when compared to those from the group with chronic mental illnesses. The respondents from the group with chronic mental illnesses have a slightly better physical health, while respondents from the group with paraplegia, without statistically significant differences, have better mental health and social relationships.

CONCLUSION: Paraplegics have a slightly better overall quality of life than chronic mental patients but the difference is not statistically significant.
\end{abstract}

Key words: quality of life, paraplegic

Correspondence:

Zdeslav Katavić, e-mail: zdeslav.katavic@gmail.com 